Article

\title{
Simultaneous Removal of Estrogens and Antibiotics from Livestock Manure Using Fenton Oxidation Technique
}

\author{
Jian Wang ${ }^{\dagger}$, Xian Zhou ${ }^{\dagger}$, Michael Gatheru Waigi ${ }^{\circledR}$, Fredrick Owino Gudda, Pengfei Cheng and \\ Wanting Ling * \\ Institute of Organic Contaminant Control and Soil Remediation, College of Resources and Environmental \\ Sciences, Nanjing Agricultural University, Nanjing 210095, China \\ * Correspondence: lingwanting@njau.edu.cn; Tel.: +86-25-84395194 \\ + These authors contributed equally to this paper.
}

Received: 17 June 2019; Accepted: 25 July 2019; Published: 28 July 2019

\begin{abstract}
The presence of estrogens and antibiotics in animal manure has raised considerable attention regarding their potential risks in both the soil system and human health. This study investigated the removal of estrogens (estriol (E3), bisphenol A (BPA), estradiol (17 $\beta$-E2), ethinyl estradiol (EE2)), and antibiotic (sulfadimethoxine (SDM)) in livestock manure using the Fenton oxidation process. Based on the removal efficiency of estrogens and antibiotics, the optimal conditions of the Fenton oxidation process were as follows: an $\mathrm{H}_{2} \mathrm{O}_{2}$ dosage of $10.5 \mathrm{mmol} / \mathrm{g}$ slurry, an $\mathrm{Fe}^{2+} / \mathrm{H}_{2} \mathrm{O}_{2}$ molar ratio of $0.067 \mathrm{~mol} / \mathrm{mol}$, a stirring rate of $100 \mathrm{rpm}$, the feeding of an identical amount of $\mathrm{H}_{2} \mathrm{O}_{2}$ in two steps (at 0 and $15 \mathrm{~min}$ ), a manure/reactor ratio of 1:25, and a reaction time of $100 \mathrm{~min}$. Under these conditions, the removal efficiencies of E3, BPA, 17 $\beta$-E2, EE2, and SDM in cow manure were $72.1 \%, 88.2 \%, 89.4 \%, 73.3 \%$, and $99.7 \%$, respectively. In the above-mentioned optimal conditions, the simultaneous removal of estrogens and antibiotic in different manure conditions led to the removal of above $70 \%$ of targeted contaminants, except for E3 in swine and chicken manure in all the manure. The findings demonstrate the useful application of the Fenton oxidation process in the concomitant removal of antibiotics and estrogens from animal manure, which reduces the associated risks to human health and environmental safety.
\end{abstract}

Keywords: antibiotic; estrogen; livestock manure; Fenton oxidation technique

\section{Introduction}

Estrogens and antibiotics are extensively used for animal growth promotion, therapeutics, and prophylactics applications [1]. However, they are poorly absorbed in animal bodies, with approximately $50-80 \%$ being excreted as parent compounds [2]. As a result, various estrogens and antibiotics are widely detected in animal manure. Globally, large amounts of livestock and poultry manures are released annually (1.1 billion tons in America, 1.6 billion tons in Europe, and 3.26 billion tons in China) [3-5]. These manures are a key access point of veterinary estrogens and antibiotics into the environment [6]. Xu et al. [7] found that the concentration of estrogens was up to $1764.3 \mu \mathrm{g} / \mathrm{kg}$ in animal manure of Jiangsu province, China. A study of the Austrian territory manure revealed that the concentration of chlortetracycline and sulfadiazine were $46 \mathrm{mg} / \mathrm{kg}$ and $91 \mathrm{mg} / \mathrm{kg}$ from swine manure, respectively [8]. These contaminants may enter soils via direct manure application as organic fertilizers, before their subsequent phyto-uptake by crops [9]. Furthermore, it may increase the chances of transferring antibiotic-resistant bacteria into humans as a result of the consumption of crops contaminated with antibiotics and estrogen $[10,11]$. 
Various treatments such as composting and anaerobic digestion have been used in the removal of antibiotics and estrogens from livestock manure $[1,10]$. However, these bio-oxidative processes do not completely remove antibiotics and estrogens from manure [9,12-14]. Zhang et al. [13] reported efficiency rates of $14.7-21.8 \%$ on estrogen removal using anaerobic digesters. In another study, Zhang et al. [14] revealed that $35.3 \%$ of detected antibiotics were still residual during 171 days of composting. It is highly desired to advance efficient removal strategies for reducing the estrogens and antibiotics levels in manures.

Recently, advanced oxidation processes (AOPs) have received huge attention as alternative and practical treatment technologies [15]. Besides, with the generation of highly active free radicals, AOPs can remove various nonbiodegradable organic compounds. The persulfate oxidation, perxone, Fenton, and ozonation are frequently studied AOPs [16,17]. Among the innumerous AOPs, Fenton oxidation process has been widely studied as an organic pollutant removal approach due to its low cost, operability at room temperature with a simple technology, high efficiency in degrading various pollutants, and non-toxic by-products production (i.e., carbon dioxide, water, and/or less hazardous intermediates) [18].

In a traditional Fenton reaction, it is known that the catalytic decomposition of $\mathrm{H}_{2} \mathrm{O}_{2}$ by $\mathrm{Fe}^{2+}$ produces free hydroxyl radicals (HO-), which have a great oxidant capacity $(2.8 \mathrm{eV})$ in the degradation of organic contaminants, as shown in Equation (1) [19]:

$$
\mathrm{H}_{2} \mathrm{O}_{2}+\mathrm{Fe}^{2+} \rightarrow \mathrm{HO} \cdot+\mathrm{OH}^{-}+\mathrm{Fe}^{3+}
$$

The excess hydrogen peroxide can react with organic radical (R.) in the presence of high concentrations of $\mathrm{H}_{2} \mathrm{O}_{2}$, which is produced from the reaction between $\mathrm{HO}$. and organic molecules to generate additional $\mathrm{HO}$. (Equations (2) and (3)). Also, $\mathrm{H}_{2} \mathrm{O}_{2}$ could react with $\mathrm{Fe}^{3+}$ and trap $\mathrm{HO}$ - to generate weaker perhydroxyl radicals $\left(\mathrm{HO}_{2} \cdot\right)$ (Equations (4) and (5)) [20]:

$$
\begin{gathered}
\mathrm{HO} \cdot+\mathrm{RH} \rightarrow \mathrm{H}_{2} \mathrm{O}+\mathrm{R} \cdot \\
\mathrm{R} \cdot+\mathrm{H}_{2} \mathrm{O}_{2} \rightarrow \mathrm{ROH}+\mathrm{HO} \cdot \\
\mathrm{Fe}^{3+}+\mathrm{H}_{2} \mathrm{O}_{2} \rightarrow \mathrm{Fe}^{2+}+\mathrm{HO}_{2} \cdot+\mathrm{H}^{+} \\
\mathrm{HO} \cdot+\mathrm{H}_{2} \mathrm{O}_{2} \rightarrow \mathrm{HO}_{2} \cdot+\mathrm{H}_{2} \mathrm{O}
\end{gathered}
$$

As an environmentally-friendly technology, some laboratory studies have shown that the Fenton process could remove estrogens and antibiotics in manure [21-24]. Sun et al. [21] reported that $97.8 \%$ of estradiol (E2) was removed in cow manure. Uslu and Balcioglu [22] found that the Fenton process in animal waste could remove up to $98.3 \%$ of oxytetracycline and $97.8 \%$ of sulfamethazine. Another study by Ben et al. [24] demonstrated that antibiotics such as sulfamethoxazole and sulfadimethoxine (SDM) could be reduced by up to $92 \%$ and $99 \%$ by Fenton's reagent, respectively. However, these studies deal with small-scale drying manure, and they did not develop a Fenton treatment equipment to remove antibiotics or estrogens in animal manure. At the same time, estrogens and veterinary antibiotics are coexistent in livestock manure, with scarce information available regarding their concomitant removal from manure by the Fenton process technique so far. Therefore, it is imperative to produce a convenient, feasible, and effective technique of concurrently removing estrogens and antibiotics from animal manure.

Given the previously mentioned reasons, this investigation aimed at attempting to develop a Fenton oxidation process for the concurrent removal of estrogens (estriol, bisphenol A, estradiol, ethinyl estradiol), and an antibiotic (sulfadimethoxine) in synthetically contaminated dairy manure. The effects of the stirring rate, volume, and modes of $\mathrm{H}_{2} \mathrm{O}_{2}$ dosage on the estrogenic and antibiotic removal efficacy were assessed. Moreover, the concomitant removal of estrogens and antibiotic, plus their physicochemical values under optimum reaction conditions in different livestock manures, were 
determined. The results can highlight a useful and convenient method that is suitable for the safe treatment of manures contaminated with estrogens and antibiotics.

\section{Results and Discussion}

\subsection{Effect of Stirring Speed on the Removal of Estrogens and Antibiotic}

The removal process of estrogens and antibiotic in the Fenton oxidation system is a solid-liquid reaction process, which is controlled by the simultaneous chemical reaction and mass transfer [25]. Therefore, it is necessary to test the effects of stirring speed on estrogens and antibiotic removal efficiency. Figure 1a-e shows the removal of E3, BPA, 17 $\beta$-E2, EE2, total estrogens, and SDM under three stirring speeds $(80 \mathrm{rpm}, 100 \mathrm{rpm}$, and $120 \mathrm{rpm}$ ) in Fenton oxidation experiments. There are various effects regarding the removal of estrogens and antibiotics under different stirring speed. For SDM, the percentage removals were $88.1 \%, 94.4 \%$, and $96.2 \%$ at stirring rates of $80 \mathrm{rpm}, 100 \mathrm{rpm}$, and $120 \mathrm{rpm}$ by Fenton oxidation, respectively (Figure 1f). Generally, the higher speed facilitated the homogenization process in the mixture, which increased the likely contact of the target pollutants with Fenton's reagent. Similar phenomena were reported, for instance, in the decolorization of rhodamine $B$ [26]. Moreover, the oxidant and the iron species could more easily reach the manure surface at a higher speed, thereby increasing the removal efficiency in the reaction.

(a)

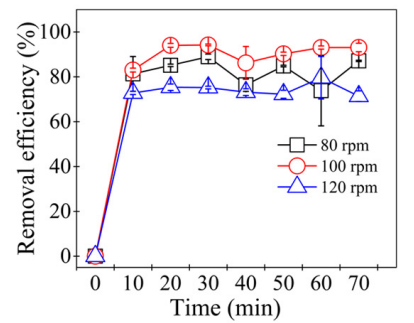

(d)

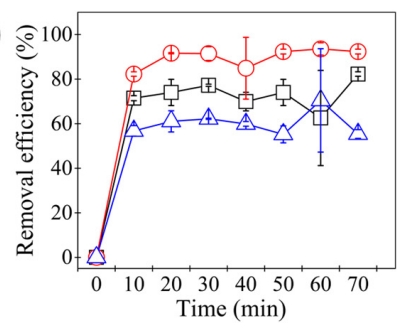

(b)

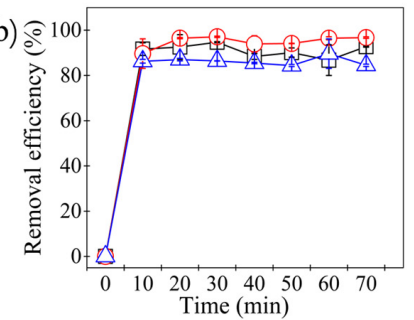

(e)

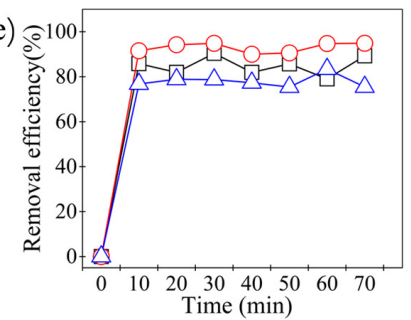

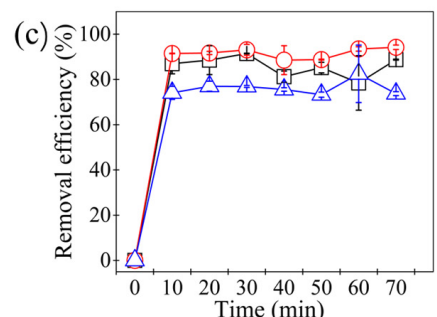

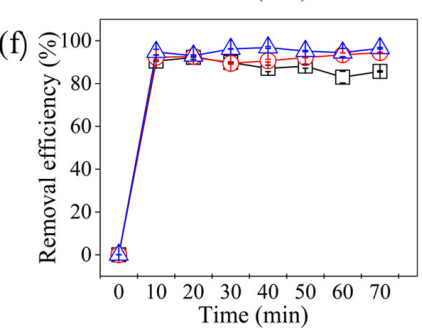

Figure 1. Effect of stirring rate on the removal efficiency of estrogens and sulfadimethoxine (SDM) from cow manure by the Fenton oxidation process. (a): Estriol (E3); (b): Bisphenol A (BPA); (c): Estradiol (17 $\beta$-E2); (d): Ethinyl estradiol (EE2); (e): Total estrogens; (f): Sulfadimethoxine (SDM). Reaction conditions: $\mathrm{H}_{2} \mathrm{O}_{2}$ dosage was $10.5 \mathrm{mmol} / \mathrm{g}$ slurry; the $\mathrm{Fe}^{2+}$ to $\mathrm{H}_{2} \mathrm{O}_{2}$ molar ratio was $0.067 \mathrm{~mol} / \mathrm{mol}$; a liquid to solids ratio of $5 \mathrm{~g} / \mathrm{g}$ dry weight; an initial $\mathrm{pH}$ value of 3.0; the weight of cow manure was $50 \mathrm{~g}$; the reaction time was $70 \mathrm{~min}$; and room temperature was $25^{\circ} \mathrm{C}$.

However, for different chemical substances, they have different mass transfer characteristics at various speed velocities. The stirring speed of $120 \mathrm{rpm}$ achieved a lower removal of all estrogens, especially EE2 (with a removal efficiency lower than 60\%) (Figure 1d). In contrast, higher elimination percentages were observed under the stirring speed of $100 \mathrm{rpm}$. Hence, there is a removal difference between estrogens and antibiotics at the same speed in the Fenton oxidation reaction. Equally, a higher speed may accelerate the generation of intermediates, which compete with test compounds for hydroxyl radicals. Synthetically, the stirring speed of $100 \mathrm{rpm}$ is considered an optimum condition to remove estrogens and antibiotics.

As observed in Figure 1a-e, under the stirring speed of $100 \mathrm{rpm}$, the removal efficiencies of these contaminants were $83 \%$ (E3), 89.6\% (BPA), 91.4\% (17 $\beta$-E2), 82.3\% (EE2), and 92.3\% (SDM) in the initial $10 \mathrm{~min}$; then, the removal becomes smooth and slow. An increase in the reaction time led to a rise of 
$3-10 \%$ in removal efficiencies. As the Fenton oxidation process is a rapid reaction, Ben et al. [24] found that the sulfonamides were rapidly degraded in the initial $2 \mathrm{~min}$, before their complete removal at $10 \mathrm{~min}$. Li and Zhang [27] showed that the degradation of estrogens was swift during the first $15 \mathrm{~min}$. From the time of dosing $\mathrm{H}_{2} \mathrm{O}_{2}$ and $\mathrm{Fe}^{2+}$, the free hydroxyl radicals (HO.) were mostly produced in the early period of the reaction, which were then immediately consumed by estrogens and antibiotics, as shown in Equation (1). Afterward, the reaction gradually ended with the depletion of $\mathrm{H}_{2} \mathrm{O}_{2}$ and $\mathrm{HO}$. Hence, an extended reaction time is beneficial to target contaminant removal.

\subsection{Effect of the Manure/Reactor Ratio on the Removal of Estrogens and Antibiotic}

It is necessary to ensure that enough space is maintained during the violent reaction process, which could keep the operator safe, as well as ensure the smooth running of the device. Therefore, the effect of manure/reactor ratio on the estrogens and antibiotic removal was evaluated at three different ratios $\left(1: 25,1: 10\right.$, and 1:6), with the reaction volume fixed at $5000 \mathrm{~mL}$, an $\mathrm{H}_{2} \mathrm{O}_{2}$ dosage of $10.5 \mathrm{mmol} / \mathrm{g}$ slurry, an $\mathrm{Fe}^{2+}$ to $\mathrm{H}_{2} \mathrm{O}_{2}$ molar ratio of $0.067 \mathrm{~mol} / \mathrm{mol}$, a liquid to solids ratio of $5 \mathrm{~g} / \mathrm{g}$ dry weight, and an initial $\mathrm{pH}$ value of 3.0. The effect of the manure/reactor ratio on the removal of estrogens and antibiotics is shown in Figure 2. A higher manure/reactor ratio resulted in lower removal efficiencies of the tested estrogens and SDM, especially E3 (33.1\% removal at a manure/reactor ratio of 1:10). It might be that too much manure could cause competition for $\mathrm{H}_{2} \mathrm{O}_{2}$ between target compounds and other organic matters in manure samples. Moreover, as an exothermic oxidation reaction, the excess heat is gathered in the reaction system when the volume of the reaction space decreased. It could decompose $\mathrm{H}_{2} \mathrm{O}_{2}$ into $\mathrm{H}_{2} \mathrm{O}$ and $\mathrm{O}_{2}$, with the lower yield of hydroxyl radicals finally inhibiting the oxidation of organics [28].

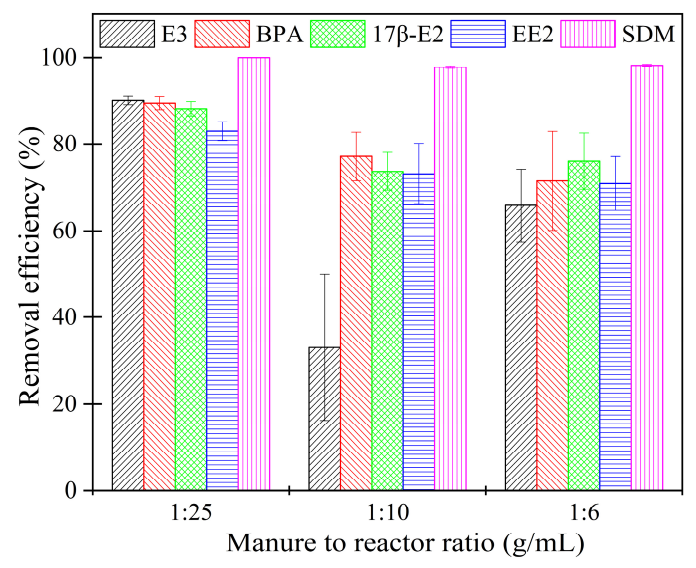

Figure 2. Effect of manure to reactor ratio $(\mathrm{g} / \mathrm{mL})$ on the removal efficiency of estrogens and SDM from cow manure. Reaction conditions: $\mathrm{H}_{2} \mathrm{O}_{2}$ dosage was $10.5 \mathrm{mmol} / \mathrm{g}$ slurry; the $\mathrm{Fe}^{2+}$ to $\mathrm{H}_{2} \mathrm{O}_{2}$ molar ratio was $0.067 \mathrm{~mol} / \mathrm{mol}$; a liquid to solids ratio of $5 \mathrm{~g} / \mathrm{g}$ dry weight; a $\mathrm{pH}$ value of 3.0; a stirring rate of $100 \mathrm{rpm}$; a fixed reaction volume of $5000 \mathrm{~mL}$; a total reaction time of $70 \mathrm{~min}$; and the room temperature was $25^{\circ} \mathrm{C}$.

On the other hand, Fenton oxidation is a dangerous reaction. With the increased manure/reactor ratio, the produced gas filled the reactor, which could have an adverse effect on the reaction [29,30], such as increase the consumption of $\mathrm{H}_{2} \mathrm{O}_{2}$, lower the removal efficiencies of target compounds, and even bring about liquid spatter, causing damage for operators. The elimination percentages achieved at a manure/reactor ratio of $1: 25$ by the Fenton oxidation process were above $90 \%$, with all of the SDM being removed under the test conditions. Hence, the manure/reactor ratio of 1:25 is an optimum condition for the Fenton oxidation technique. 


\subsection{Effect of $\mathrm{H}_{2} \mathrm{O}_{2}$ Dosification on Estrogens and Antibiotic Removal}

$\mathrm{H}_{2} \mathrm{O}_{2}$ could be dosified either at the beginning of the reaction or during the process [31]. Different adding modes of hydrogen peroxide corresponded to a change in the $\mathrm{H}_{2} \mathrm{O}_{2}$ dosage and $\mathrm{H}_{2} \mathrm{O}_{2} / \mathrm{Fe}^{2+}$ ratio, which subsequently led to the various oxidative removal of estrogens and SDM from cow manure. In order to investigate the effect of feeding modes, Fenton's reagent was fed with four different methods as follows: ferrous iron (the $\mathrm{Fe}^{2+}$ to $\mathrm{H}_{2} \mathrm{O}_{2}$ molar ratio was $0.067 \mathrm{~mol} / \mathrm{mol}$ ) was added in a single step (at $0 \mathrm{~min}$ ), but the same amount of $\mathrm{H}_{2} \mathrm{O}_{2}$ for the best removal relationship obtained previously ( $10.5 \mathrm{mmol} / \mathrm{g}$ slurry) was fed in phases of two steps (at 0 and $15 \mathrm{~min}$, the $\mathrm{H}_{2} \mathrm{O}_{2}$ dosage was $5.0 \mathrm{mmol} / \mathrm{g}$ slurry, with a $\mathrm{H}_{2} \mathrm{O}_{2} / \mathrm{Fe}^{2+}$ ratio of $0.14 \mathrm{~mol} / \mathrm{mol}$ ), three steps (at 0,15 , and $30 \mathrm{~min}$, every $\mathrm{H}_{2} \mathrm{O}_{2}$ dosage was $3.5 \mathrm{mmol} / \mathrm{g}$ slurry, with a $\mathrm{H}_{2} \mathrm{O}_{2} / \mathrm{Fe}^{2+}$ ratio of $0.2 \mathrm{~mol} / \mathrm{mol}$ ), five steps (at $0,10,20,30$, and $40 \mathrm{~min}$, every $\mathrm{H}_{2} \mathrm{O}_{2}$ dosage was $2.63 \mathrm{mmol} / \mathrm{g}$ slurry, with a $\mathrm{H}_{2} \mathrm{O}_{2} / \mathrm{Fe}^{2+}$ ratio of $0.27 \mathrm{~mol} / \mathrm{mol}$ ), or 10 steps (at 0 , and every $10 \mathrm{~min}$, each $\mathrm{H}_{2} \mathrm{O}_{2}$ dosage was $1.05 \mathrm{mmol} / \mathrm{g}$ slurry, with a $\mathrm{H}_{2} \mathrm{O}_{2} / \mathrm{Fe}^{2+}$ ratio of $0.67 \mathrm{~mol} / \mathrm{mol}$ ). The total reaction time was extended to $100 \mathrm{~min}$.

The effect of the modes of $\mathrm{H}_{2} \mathrm{O}_{2}$ dosage on the removal of the tested estrogens and SDM by the Fenton oxidation process was given in Figure 3. When hydrogen peroxide was added at two times, better chemical compounds removal was obtained than the other addition modes of hydrogen peroxide. The same result was found by Zhang et al. in the Fenton treatment [32]. The higher removal efficiencies of BPA, $17 \beta$-E2, EE2, and SDM were $88.2 \%, 89.4 \%, 73.3 \%$, and $100 \%$, respectively in cow manure. The single-adding dosage of $\mathrm{H}_{2} \mathrm{O}_{2}$ in fewer steps was higher than that in more additional steps, which could account for the rapid and efficient generation of HO-, as well as other active radicals such as $\mathrm{HO}_{2}$. to remove contaminants in manure effectively, as shown in Equation (4). On the contrary, some previous studies have been reported that more feeding steps of hydrogen peroxide could increase the removal of organic compounds. It means that the relative lower $\mathrm{H}_{2} \mathrm{O}_{2}$ concentration at stepwise addition could reduce the detrimental effect of hydroxyl radical scavenging [31,33,34]. However, at the same time, lower hydrogen peroxide concentration could compete by other organic substances under a complex matrix of manure.

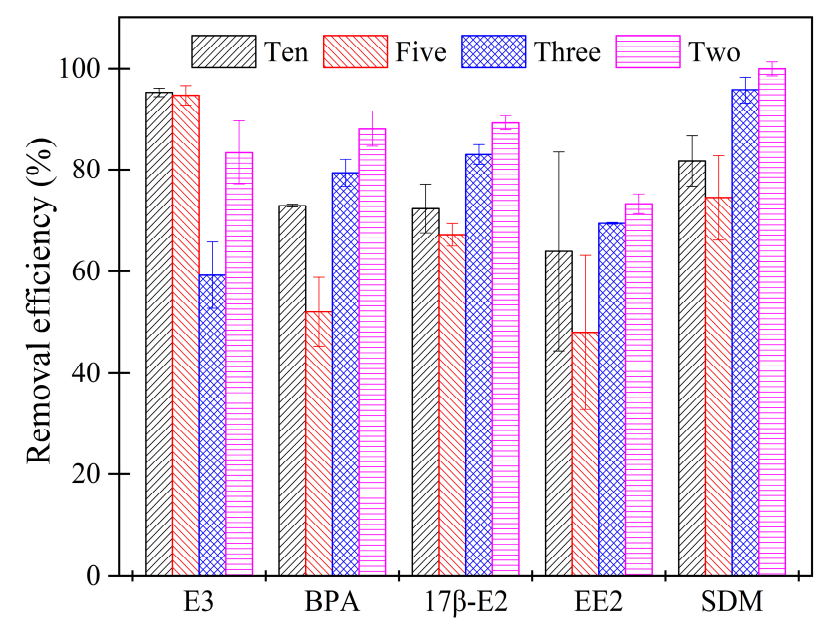

Figure 3. Effect of $\mathrm{H}_{2} \mathrm{O}_{2}$ adding modes on the removal efficiency of estrogens and SDM from cow manure. Reaction conditions: the $\mathrm{H}_{2} \mathrm{O}_{2}$ dosage was $10.5 \mathrm{mmol} / \mathrm{g}$ slurry; the $\mathrm{Fe}^{2+}$ to $\mathrm{H}_{2} \mathrm{O}_{2}$ molar ratio was $0.067 \mathrm{~mol} / \mathrm{mol}$; a liquid to solids ratio of $5 \mathrm{~g} / \mathrm{g}$ dry weight; the $\mathrm{pH}$ value was 3.0 ; the stirring rate was $100 \mathrm{rpm}$; the solid to volume ratio was 1:25; the total reaction time was $100 \mathrm{~min}$; and the room temperature was $25^{\circ} \mathrm{C}$. Each test was repeated three times, and error bars represent standard deviations (SD).

Besides, in these methods, the total dosage ratio was kept at this value, i.e., $\mathrm{Fe}$ (II)/ $\mathrm{H}_{2} \mathrm{O}_{2}=$ $0.067 \mathrm{~m} / \mathrm{m}$. Hydrogen peroxide was added at different times, while ferrous iron was applied in a single step. This means that $\mathrm{Fe}^{2+}$ was overdosed, compared to $\mathrm{H}_{2} \mathrm{O}_{2}$ in the first addition. At higher 
concentrations of ferrous iron, $\mathrm{HO}$. radicals were scavenged by reacting with excess $\mathrm{Fe}^{2+}$, as shown in Equation (6) [35]. Similar results were reported by Li and Zhang [27] and Uslu et al. [22].

$$
\mathrm{Fe}^{2+}+\cdot \mathrm{OH} \rightarrow \mathrm{Fe}^{3+}+\mathrm{OH}^{-}
$$

For E3, when hydrogen peroxide was added in five or 10 steps, up to $95 \%$ of E3 was eliminated from cow manure. In all likelihood, E3 could have intense competition for $\mathrm{HO}$, provided there is additional dosage. The result suggested that less $\mathrm{H}_{2} \mathrm{O}_{2}$ addition steps could take advantage of reducing the estrogens and antibiotics from dairy manure in the Fenton reaction. Therefore, the optimum mode of $\mathrm{H}_{2} \mathrm{O}_{2}$ addition frequency was two-step in the Fenton oxidation technique.

\subsection{Effect of Different Types of Manure on the Removal of Tested Estrogens and SDM under Optimum Reaction Conditions}

Six manure samples were collected from six livestock farms to verify the effect of optimum reaction conditions on the removal efficiencies of estrogens and antibiotics in different animal manures. Target organic compounds were detected at different levels, as shown in Table 1. In all the animal manures, the concentration of SDM was lower than each estrogen. E3 showed the highest level amongst the four estrogens.

Table 1. The initial concentration of estrogens and SDM in livestock feces $(\mu \mathrm{g} / \mathrm{kg})$.

\begin{tabular}{ccccccc}
\hline \multirow{2}{*}{ Sample } & \multicolumn{6}{c}{ The Initial Concentration of Estrogens and SDM in Livestock Feces $(\boldsymbol{\mu g} / \mathbf{k g})$} \\
\cline { 2 - 7 } & E3 & BPA & 17 $\beta$-E2 & EE2 & $\sum E$ & SDM \\
\hline D1 & $6765 \pm 848^{1}$ & $17 \pm 0$ & $23 \pm 22$ & $188 \pm 42$ & $6982 \pm 897$ & $5.6 \pm 0.92$ \\
D2 & $1115 \pm 155$ & $0.81 \pm 0.77$ & ND $^{2}$ & $112 \pm 0$ & $1153 \pm 183$ & $1.61 \pm 0.02$ \\
S1 & $592 \pm 81$ & $137 \pm 17$ & $106 \pm 21$ & ND & $568 \pm 78$ & $7.58 \pm 0.86$ \\
S2 & $844 \pm 165$ & ND & $152 \pm 76$ & ND & $999 \pm 151$ & $40.89 \pm 9.82$ \\
C1 & $53 \pm 62$ & ND & $1.84 \pm 2.6$ & ND & $55 \pm 61$ & $2.8 \pm 0.22$ \\
C2 & $40 \pm 22$ & $4 \pm 0$ & $19 \pm 14$ & ND & $60 \pm 26$ & $1.22 \pm 0.11$ \\
\hline
\end{tabular}

D1-2, S1-2, and C1-2 represent dairy manure, swine manure, and chicken manure, respectively. ${ }^{1}$ Mean \pm standard deviation $(n=3) .{ }^{2}$ Not detected.

Table 2 shows the residual concentrations of estrogens and SDM in six different livestock feces after the oxidation reaction. Under optimal oxidation conditions, the SDM was eliminated in four manure samples, and removal levels of above $46.2 \%$ were observed in all estrogens (Table 3). In dairy manure samples, the Fenton oxidation reaction could work well in removing five organic compounds from dairy manure. The removal efficiencies were above 70\%; BPA and EE2 were removed using the Fenton oxidation process. In swine and chicken manure samples, it was fluctuant for the removal of estrogens. 
Table 2. The residual concentration of estrogens and SDM in livestock feces after Fenton oxidation $(\mu \mathrm{g} / \mathrm{kg})$.

\begin{tabular}{ccccccc}
\hline \multirow{2}{*}{ Sample } & \multicolumn{5}{c}{ The Residual Concentration of Estrogens and SDM in Livestock Feces $(\boldsymbol{\mu g} / \mathbf{k g})$} \\
\cline { 2 - 6 } & E3 & BPA & $\mathbf{1 7} \beta$-E2 & EE2 & $\sum$ E & SDM \\
\hline D1 & $112 \pm 121^{1}$ & ND $^{2}$ & $0.05 \pm 0.07$ & $97 \pm 0$ & $145 \pm 98$ & $1.48 \pm 0.11$ \\
D2 & $50 \pm 36$ & ND & ND & ND & $50 \pm 36$ & ND \\
S1 & $175 \pm 24$ & $34 \pm 8$ & $37 \pm 0$ & ND & $234 \pm 33$ & ND \\
S2 & $58 \pm 35$ & ND & $21 \pm 0$ & ND & $65 \pm 27$ & $10.7 \pm 1.15$ \\
C1 & $36 \pm 23$ & ND & ND & ND & $36 \pm 23$ & ND \\
C2 & $4 \pm 3$ & $13 \pm 0$ & $2.72 \pm 3.57$ & ND & $11 \pm 8$ & ND \\
\hline
\end{tabular}

Reaction conditions: The $\mathrm{H}_{2} \mathrm{O}_{2}$ dosage was $10.5 \mathrm{mmol} / \mathrm{g}$ slurry; the $\mathrm{Fe}^{2+}$ to $\mathrm{H}_{2} \mathrm{O}_{2}$ molar ratio was $0.067 \mathrm{~mol} / \mathrm{mol}$; the liquid to solids ratio was $5 \mathrm{~g} / \mathrm{g}$ dry weight; the $\mathrm{pH}$ value was 3.0; the stirring rate was $100 \mathrm{rpm}$; the solid to volume ratio was 1:25; an identical amount of $\mathrm{H}_{2} \mathrm{O}_{2}$ was fed in two steps (at 0 and $15 \mathrm{~min}$ ); and the total reaction time was $100 \mathrm{~min}$. D1-2, S1-2, and C1-2 represent dairy manure, swine manure, and chicken manure, respectively. ${ }^{1}$ Mean \pm standard deviation $(n=3) .{ }^{2}$ Not detected.

Table 3. The removal efficiencies of estrogens and SDM in livestock feces under the Fenton oxidation process $(\%)$.

\begin{tabular}{ccccccc}
\hline \multirow{2}{*}{ Sample } & \multicolumn{6}{c}{ The Removal Efficiency of Estrogens and SDM in Livestock Feces (\%) } \\
\cline { 2 - 7 } & E3 & BPA & $\mathbf{1 7 \beta - E 2}$ & EE2 & $\sum$ E & SDM \\
\hline D1 & 97.5 & 100 & 99.8 & 82.7 & 97.9 & 73.5 \\
D2 & 95.5 & - & - & 100 & 95.7 & 100 \\
S1 & 46.2 & 75.4 & 88.5 & - & 60.5 & 100 \\
S2 & 93.1 & - & 95.6 & - & 93.5 & 73.8 \\
C1 & 56.4 & - & 100 & - & 57.9 & 100 \\
C2 & 85.5 & - & 78.0 & - & 81.6 & 100 \\
\hline
\end{tabular}

Reaction conditions: the $\mathrm{H}_{2} \mathrm{O}_{2}$ dosage was $10.5 \mathrm{mmol} / \mathrm{g}$ slurry; the $\mathrm{Fe}^{2+}$ to $\mathrm{H}_{2} \mathrm{O}_{2}$ molar ratio was $0.067 \mathrm{~mol} / \mathrm{mol}$; the liquid to solids ratio was $5 \mathrm{~g} / \mathrm{g}$ dry weight; the $\mathrm{pH}$ value was 3.0; the stirring rate was $100 \mathrm{rpm}$; the solid to volume ratio was 1:25; an identical amount of $\mathrm{H}_{2} \mathrm{O}_{2}$ was fed in two steps (at 0 and $15 \mathrm{~min}$ ); and the reaction time was 100 min. D1-2, S1-2, and C1-2 represent dairy manure, swine manure, and chicken manure, respectively.

Based on the above result, some target compounds remained in the slurry under the optimal Fenton oxidation conditions, but it was unclear whether the residue was in manure or filtrate. However, a study conducted by Uslu et al. [22] reported that only $1.7 \%$ of the oxytetracycline (OTC) and $2.2 \%$ of the sulfamethazine (SMZ) remained in the filtrate, even at optimal conditions. This finding indicated that lower target compounds in the filtrate were residual, in that, after the reaction, there was a low filtrate volume due to the high water-absorbing property of manure [36], and this may not have had a significant negative impact on the environment.

For dairy manure samples, Fenton reagents could fully contact with the contaminants contained in solids due to their high water-absorbing property (7.17 g/g dry weight) [36]. Conversely, in swine and chicken manure (the water-absorbing values were $3.36 \mathrm{~g} / \mathrm{g}$ dry weight and $4.62 \mathrm{~g} / \mathrm{g}$ dry weight, respectively), the Fenton oxidation reagent was preferentially consumed by organic matter in the liquid phase, which led to competition between various estrogen molecules and other intermediate products during the oxidation reaction process. Hence, the optimum conditions of the Fenton oxidation technique were more suitable for application in dairy manure.

Moreover, the mainly physicochemical values in livestock manure, before and after Fenton oxidation, are given in Table 4. The Fenton oxidation process is non-selective in the removal of organic or inorganic contaminants. In order to study the effect of the reaction on the removal of total organic compounds (i.e., humus), the total organic carbon (TOC) before and after Fenton oxidation was detected. In Table 4, the TOC decreased by approximately 14.1-34.3\%. Nieto et al. [37] reported that the Fenton-like process is efficient in the reduction of TOC. This result corresponded to Sillanpaa 
et al. [38]. Furthermore, this result indicated that there are few numbers of organic matter in manure degraded into $\mathrm{CO}_{2}$ and $\mathrm{H}_{2} \mathrm{O}$ after the Fenton oxidation reaction. In the Fenton reaction, those organic compounds could be parent substances or degradation intermediates in manure samples. For five targeted compounds, they could be annihilated or degraded into intermediates to consume free radicals.

Table 4. Physicochemical values in livestock feces before (B) and after (A) Fenton oxidation (g/kg).

\begin{tabular}{ccccccccccc}
\hline \multirow{2}{*}{ Sample } & \multicolumn{2}{c}{ TOC } & \multicolumn{2}{c}{ TP } & \multicolumn{2}{c}{ TK } & \multicolumn{2}{c}{ TN } & \multicolumn{2}{c}{ Fe } \\
\cline { 2 - 11 } & B & A & B & A & B & A & B & A & B & A \\
\hline D1 & 556.3 & 464.1 & 24.2 & 19.3 & 2.41 & 2.00 & 24.7 & 19.6 & 0.48 & 1.60 \\
D2 & 528.3 & 378.8 & 21.7 & 17.5 & 3.62 & 4.00 & 18.2 & 16.3 & 0.62 & 1.21 \\
S1 & 573.5 & 492.8 & 83.0 & 62.6 & 0.94 & 0.71 & 26.2 & 23.6 & 0.46 & 1.52 \\
S2 & 534.1 & 350.9 & 51.4 & 48.6 & 3.50 & 3.22 & 28.6 & 25.0 & 0.64 & 1.64 \\
C1 & 481.1 & 368.1 & 24.7 & 23.9 & 3.16 & 2.63 & 28.5 & 23.8 & 0.45 & 1.51 \\
C2 & 564.7 & 388.4 & 39.3 & 34.2 & 3.30 & 2.63 & 22.9 & 17.6 & 0.81 & 1.43 \\
\hline
\end{tabular}

TOC, TP, TK, and TN represent total organic carbon, total phosphorus, total potassium, and total nitrogen, respectively.

Nevertheless, it was challenging to identify the degradation by-products of estrogens and antibiotics in the complex matrix of animal manure, which also contained a variety of background organic substances. Li and Zhang [27] found that the Fenton oxidation could oxidize phenol structures of estrogens to cyclohexanone moieties and quinone-like structures over $120 \mathrm{~min}$ of reaction in water, which are less active than the original target estrogens (E1, E2, E3, and EE2). Ben et al. [24] measured the acute toxicity of reaction solution, explaining the reduction of toxicity in swine wastewater.

The total phosphorus (TP), total potassium (TK), and total nitrogen (TN) as an evaluation index of manure were measured before and after Fenton oxidation. As described in Table 4, the total phosphorus (TP) values decreased by about $25.5 \%$ during the reaction. For TK and TN, smaller changes were observed in animal manure during the Fenton oxidation process. In the reaction, $\mathrm{Fe}^{3+}$ has a stronger affinity for $\mathrm{PO}_{4}{ }^{3-}$, leading to the straightforward generation of insoluble products such as $\mathrm{FeHPO}_{4}$ which may decrease the concentration of TP in livestock manure. For iron, it increased by $76.5-236 \%$ after the oxidation reaction. Usually, the contents are $20-30 \mathrm{~g} / \mathrm{kg}$ in farmland [39]. Therefore, the increased Fe could not cause a minor hazard in agriculture after the application to the soil environment.

\section{Materials and Methods}

\subsection{Chemicals}

The studied estrogenic and antibacterial substances were: ethinyl estradiol (EE2, Aladdin, Los Angeles, CA, USA 98\%), $\beta$-estradiol (17 $\beta$-E2, Aladdin, Los Angeles, CA, USA, 98\%), bisphenol A (BPA, Aladdin, Los Angeles, CA, USA, 97\%), estriol (E3, Aladdin, Los Angeles, CA, USA, 98\%) and sulfadimethoxine (SDM, TCI, Tokyo, Japan, 98\%). The key physicochemical properties are shown in Table 5. The HPLC/MS grade of formic acid, methanol (MeOH), and acetonitrile (ACN) were purchased from Thermo Fisher Scientific (Houston, TX, USA). Hydrogen peroxide solution $\left(\mathrm{H}_{2} \mathrm{O}_{2}\right.$, $30 \%, w / w)$, ferrous sulfate $\left(\mathrm{FeSO}_{4} \cdot 7 \mathrm{H}_{2} \mathrm{O}\right)$, citric acid $\left(\mathrm{C}_{6} \mathrm{H}_{8} \mathrm{O}_{7}\right)$, and ethyl acetate were all obtained from the Sinopharm Chemical Reagents Company (Shanghai, China).

The stock solutions of E3, BPA, $17 \beta-\mathrm{E} 2$, EE2, and SDM were prepared in methanol at a concentration of $1 \mathrm{mg} / \mathrm{mL}$ and stored at $-18{ }^{\circ} \mathrm{C}$ in a dark volumetric flask. A fresh stock solution was prepared every month. Working estrogenic mixtures of $10 \mathrm{mg} / \mathrm{L}$ were prepared by dilution from the stock solutions with methanol, stored at $4{ }^{\circ} \mathrm{C}$, and these mixed standards were used in recovery experiments and the preparation of calibration standards. They were freshly prepared each week. 
Table 5. The physicochemical properties of E3, BPA, 17 $\beta-E 2$, EE2, and SDM.

\begin{tabular}{|c|c|c|c|c|}
\hline Substances & MS 1 & $\mathrm{MW}^{2}(\mathrm{~g} / \mathrm{mol})$ & $\mathrm{pKa}^{3}$ & $\operatorname{logKow}{ }^{4}$ \\
\hline Estriol (E3) & & 288.38 & 10.4 & 2.6 \\
\hline 17beta-Estradiol (17ß-E2) & & 272.38 & 10.5 & 3.1 \\
\hline Bisphenol A (BPA) & & 228.29 & 10.7 & 3.94 \\
\hline Ethinyloestradiol (EE2) & & 296.40 & 11.3 & 3.9 \\
\hline Sulfadimethoxine (SDM) & & 310.34 & 6.08 & 1.63 \\
\hline
\end{tabular}

${ }^{1} \mathrm{MS}$ represented molecular structure; ${ }^{2} \mathrm{MW}$ represented molecular weight; ${ }^{3} \mathrm{pKa}$ means acidity constant; ${ }^{4} \operatorname{logKow}$ is the ratio of the concentration of a solute between water and octanol.

\subsection{Manure}

Cow manure was obtained from a large-scale farm near Nanjing. After air drying, manure was sieved to $0.9 \mathrm{~mm}$ and stored at room temperature until its utilization in the treatment experiments. The obtained manure samples were contaminated by spiking with $1 \mathrm{mg} / \mathrm{mL}$ of estrogens and SDM stock solutions. The initial concentrations of E3, BPA, 17ß-E2, EE2, and SDM were each $1 \mathrm{mg} / \mathrm{kg}$ of dry manure. After thorough mixing, the contaminated manure samples were allowed to equilibrate for 3 days away from the light, in a cool ventilated place.

At the same time, two typical dairy manure samples (D1 and D2), two typical swine manure samples (S1 and S2), and two chicken manure samples (C1 and C2) in Jiangsu Province of eastern China were sampled, in order to investigate the removal efficiencies of estrogens and SDM from different manures by Fenton reaction. The initial concentrations of estrogens and SDM were detected, as shown in Table 1.

\subsection{Fenton Oxidation of Manure}

Figure 4 shows the flowchart of the Fenton oxidation process to remove the estrogens and SDM. At room temperature, $50 \mathrm{~g}$ of a freeze-dried manure sample was weighed before being put into the Fenton reaction system, consisting of a 5000-mL glass flask, an injector tube, an exhaust tube, and a discharge tube. With the stirrer opened, $0.5 \mathrm{~mol} / \mathrm{L}$ of citric acid adjusted $\mathrm{pH}$ to 3.0-4.0, distilled water, and Fenton reagent were slowly added to the Fenton oxidation system to make a final $\mathrm{H}_{2} \mathrm{O}_{2}$ concentration of $10.5 \mathrm{mmol} / \mathrm{g}$ slurry in the manure, and a Fe ${ }^{2+} / \mathrm{H}_{2} \mathrm{O}_{2}$ molar ratio of $0.067 \mathrm{~mol} / \mathrm{mol}$, and the liquid to solids ratio of $5 \mathrm{~g} / \mathrm{g}$ dry weight. These parameters were determined as cited [21]. In this study, there was little filtrate due to the higher water-absorbing quality of dry manure $(7.17 \mathrm{~g} / \mathrm{g}$ dry weight), which corresponded to Fei et al. [36]; therefore, we did not do a solid-liquid separation. 


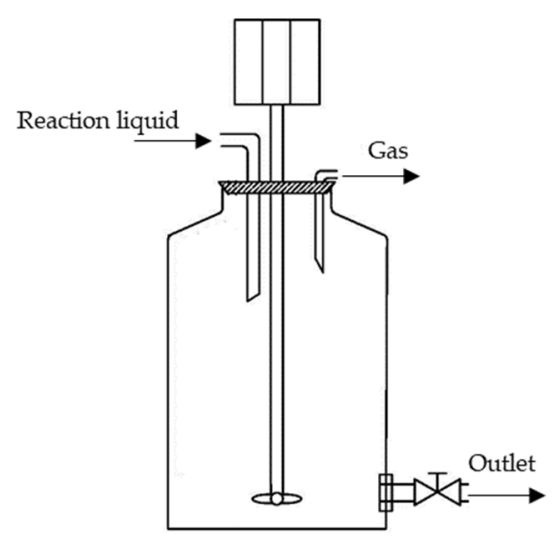

Figure 4. Flowchart of Fenton oxidation removing estrogens and SDM in cow manure.

Throughout the reactions, three manure slurry samples were taken and analyzed after freeze-drying in all the experiments, the standard deviations (SDs), obtained from three parallel samples, are shown in the figures as error bars in the following section.

\subsection{Estrogens and SDM Analysis}

\subsubsection{Estrogens Analysis}

First, $1 \mathrm{~g}$ of each manure sample was weighed into a 40-mL glass tube. Then, $20 \mathrm{~mL}$ of ethyl acetate was added into each tube, followed by mixing on a vortex mixer for $30 \mathrm{~s}$. Then, all the glass tubes were ultrasonicated for $30 \mathrm{~min}$ at $80 \mathrm{kHz}$, and centrifuged at $4000 \mathrm{rpm}$ for $30 \mathrm{~min}$. The supernatant from each tube was transferred into a 40-mL glass tube. Afterward, the extraction step was repeated. The extract was evaporated under a gentle stream of nitrogen at $40{ }^{\circ} \mathrm{C}$ to remove most of the ethyl acetate and diluted to $\sim 50 \mathrm{~mL}$ with reagent water. Then, the aqueous extract was purified by passage through C18 columns ( $200 \mathrm{mg}, 6 \mathrm{~mL}$ ) to concentrate the estrogens. The analytes were eluted from the column using $12 \mathrm{~mL}$ of methanol and ethyl acetate $(v: v=1: 1)$, and then concentrated to dryness under nitrogen flows. Finally, the residue was dissolved in $2 \mathrm{~mL}$ of methanol for HPLC-FLD (high performance liquid chromatography-fluorescent detector) analysis.

Four estrogens were detected using HPLC-FLD (LC-20AT, Shimadzu, Japan). The analytical column Inertsil ODS-SP C18 $(5 \mu \mathrm{m}, 250 \times 4.6 \mathrm{~mm})$ equipped with an ODS (Octadecylsilyl) guard column Inertsil ODS-SP $(5 \mu \mathrm{m}, 10 \times 4.0 \mathrm{~mm})$ was used. The separation was performed using a gradient elution mode as a flow rate of $0.8 \mathrm{~mL} / \mathrm{min}$ consisting of $20 \%$ methanol $(\mathrm{MeOH})$ (solvent $\mathrm{A}$ ), $30 \%$ acetonitrile (ACN) (solvent B), and 50\% water (solvent C). The excitation and emission wavelengths were set at $280 \mathrm{~nm}$ and $310 \mathrm{~nm}$. The chromatogram of uncontaminated manure was also recorded and compared with that of the contaminated manure sample (with E3, BPA, 17 $\beta-E 2$, and EE2), as shown in Figure 5. As seen in Figure 5, the chromatogram of uncontaminated manure was remarkably clean, and no interference peak was detected at the wavelength at which estrogens were determined. Recovery tests for estrogens were carried out at three concentration levels $(50 \mu \mathrm{g} / \mathrm{kg}, 400 \mu \mathrm{g} / \mathrm{kg}$, and $1000 \mu \mathrm{g} / \mathrm{kg})$, resulting in an average recovery of $75.1-91.1 \%(n=3)$.

\subsubsection{SDM Analysis}

The extraction of SDM in manure samples was performed according to the method described by Zhao et al. with some modifications [40]. A gram of freeze-dried sample was intensely vortexed with $8 \mathrm{~mL}$ of methanol in a 40-mL tube. Then, the sample was marinated in methanol overnight in the dark at $4{ }^{\circ} \mathrm{C}$ before analyzing the SDM content. The sample was shaken at $250 \mathrm{rpm}$ in a thermostat shaker at $30^{\circ} \mathrm{C}$ for $30 \mathrm{~min}$ and centrifuged for $10 \mathrm{~min}$ at $8000 \mathrm{rpm}$. The supernatant was decanted into a 40-mL glass tube. Afterwards, the extraction was repeated twice with $6 \mathrm{~mL}$ of methanol. The extract 
was evaporated under a gentle stream of nitrogen at $40{ }^{\circ} \mathrm{C}$, and the residue was dissolved in $1 \mathrm{~mL}$ of $0.02 \mathrm{~mol} / \mathrm{L}$ acetate buffer $(\mathrm{pH}=4.75)$ for HPLC analysis.

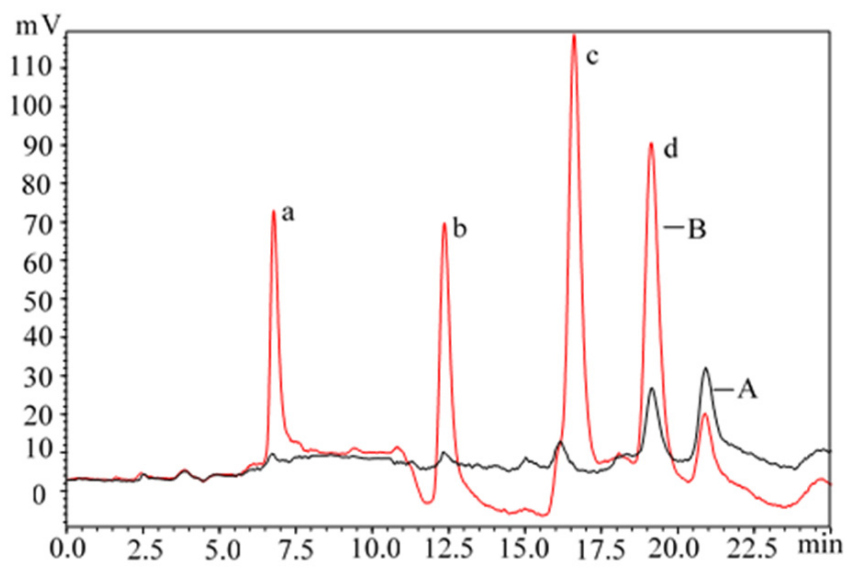

Figure 5. Representative chromatogram of manure (A) and estrogens-contaminated manure at $1 \mathrm{mg} / \mathrm{kg}$ (B). A and B represented a real manure sample and an artificially contaminated manure sample. Its effect could be ignored during HPLC analysis. Note: (a): E3, Retention time $=6.75$; (b): BPA, Retention time $=12.385 ;(c): 17 \beta-E 2$, Retention time $=16.657 ;(d)$ : EE2, Retention time $=19.188$.

A Shimadzu LC-20AT (HPLC) was used for quantitative analysis. The analytical column (Inertsil ODS-SP C18 $(5 \mu \mathrm{m}, 250 \times 4.6 \mathrm{~mm})$ equipped with an ODS guard column was used for separation. The mobile phase was composed of $70 \%$ water containing $0.1 \%$ formic acid and $30 \%$ acetonitrile. The operation wavelength was set at $270 \mathrm{~nm}$ with a reference of $360 \mathrm{~nm}$. Linearity $(\mathrm{Y}=6328.2 \mathrm{X}+14.937)$ with correlation coefficients greater than 0.9999 were observed by the HPLC-UV detection for the SDM at $10.00-2000.00 \mu \mathrm{g} / \mathrm{L}$. The LOD (limit of detection) and LOQ (limit of quantitation) of SDM in manure were calculated in $\mathrm{S} / \mathrm{N}=3$ and $\mathrm{S} / \mathrm{N}=10$; they were $2.03 \mu \mathrm{g} / \mathrm{kg}$ and $6.76 \mu \mathrm{g} / \mathrm{kg}$, respectively.

The chromatograms of uncontaminated manure and SDM-contaminated manure sample are depicted in Figure 6. Recovery tests for SDM were carried out at two concentration levels $(500 \mu \mathrm{g} / \mathrm{kg}$ and $1000 \mu \mathrm{g} / \mathrm{kg})$, resulting in an average recovery of $77.5-112 \%(n=3)$.

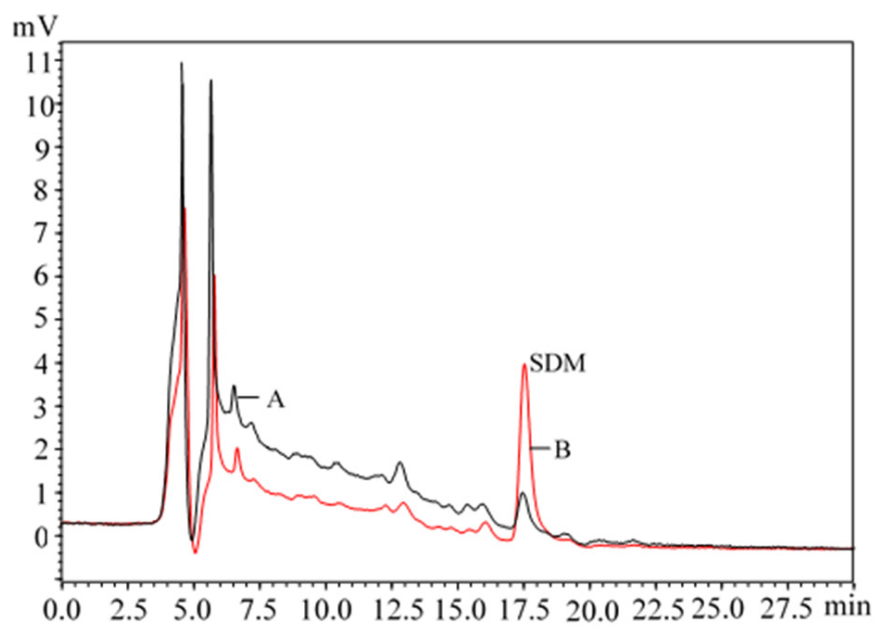

Figure 6. Representative chromatogram of manure (A) and SDM-contaminated manure at $5 \mathrm{mg} / \mathrm{kg}$ (B). $A$ and $B$ represented real manure sample and artificial contaminated manure sample. Its effects could be ignored during the HPLC analysis. Note: SDM, Retention time $=17.558$. 


\subsection{Other Chemical Analyses}

The phosphorus $(\mathrm{P})$, potassium $(\mathrm{K})$, and iron $(\mathrm{Fe})$ contents in manure were analyzed in the liquid phase by ICP-OES (inductively coupled plasma-optical emission spectrometry, Agilent model 5100 series, Palo Alto, CA., USA). The $\mathrm{pH}$ was measured using a $\mathrm{pH}$ probe with a mixture slurry at $\mathrm{H}_{2} \mathrm{O}$ to dry sample ratio of 1:5. The total organic carbon (TOC) in the manure was determined according to the dichromate method [41]. Finally, nitrogen $(\mathrm{N})$ in the manure and treated manure was determined with a flow auto-analyzer.

\subsection{Data Analysis}

The removal efficiency of target contaminants during Fenton oxidation was calculated using the following equation:

$$
\text { Removal efficiency }(\%)=\left(C_{i}-C_{t}\right) / C_{i} \times 100 \%
$$

where $C_{i}$ and $C_{t}$ mean the concentration of target contaminants at the start and during the Fenton process in animal manure, respectively.

Each data point in the figures represents an average value. The standard deviations (SDs), obtained from three parallel samples, are shown in the figures as error bars.

\section{Conclusions}

This study developed a Fenton oxidation technique for removing estrogens (E3, BPA, 17 $\beta$-E2, and EE2) and antibiotic (SDM) from cow manure. The reaction conditions of the Fenton oxidation were optimized to ensure a high removal efficiency of estrogens and antibiotic from cow manure. These include a manure/reactor ratio of 1:25, a stirring rate of $100 \mathrm{rpm}$, an equal amount of $\mathrm{H}_{2} \mathrm{O}_{2}$ being fed in two steps (at 0 and $15 \mathrm{~min}$ ), an $\mathrm{H}_{2} \mathrm{O}_{2}$ dosage of $10.5 \mathrm{mmol} / \mathrm{g}$ slurry, an $\mathrm{Fe}^{2+} / \mathrm{H}_{2} \mathrm{O}_{2}$ molar ratio of $0.067 \mathrm{~mol} / \mathrm{mol}$, and a reaction time of $100 \mathrm{~min}$ in a room temperature range of 20 to $30^{\circ} \mathrm{C}$. Under these optimal conditions, the obtained high removal efficiencies of E3, BPA, 17 $\beta$-E2, EE2, and SDM were $72.1 \%, 88.2 \%, 89.4 \%, 73.3 \%$, and $99.7 \%$, respectively. In actual manure samples, the Fenton oxidation technique could effectively remove the five target organic compounds under optimum conditions. These results show that the Fenton oxidation technique, as a current livestock manure treatment method, would be convenient and useful in the concomitant removal of estrogens and antibiotics from livestock manure. These findings provide valuable insight into the reduction of the threat posed by environmental estrogens and antibiotics to human health and environmental safety. Further studies are required in order to understand the degradation pathways of the target organic compounds during Fenton oxidation, the relationship between the removal and molecular structure, and the reuse of the catalyst in the filtrate.

Author Contributions: The experimental work was designed and supported by X.Z. and W.L.; X.Z. and J.W. analyzed the data; J.W., X.Z., M.G.W., and W.L. wrote the paper. X.Z. and W.L. contributed reagents/materials/analysis tools, and all other material support; the manuscript was amended and supplemented by all authors. All authors have approved the final version of the manuscript.

Funding: This work was financially supported by the National Natural Science Foundation of China (41771523), and the National Key R\&D Program of China (2016YFD0800203).

Conflicts of Interest: The authors declare no competing interests.

\section{References}

1. Ramaswamy, J.; Prasher, S.O.; Patel, R.M.; Hussain, S.A.; Barrington, S.F. The effect of composting on the degradation of a veterinary pharmaceutical. Bioresour. Technol. 2009, 101, 2294-2299. [CrossRef]

2. Halling-Sørensen, B.; Sengeløv, G.; Tjørnelund, J. Toxicity of tetracyclines and tetracycline degradation products to environmentally relevant bacteria, including selected tetracycline-resistant bacteria. Arch. Environ. Contam. Toxicol. 2002, 42, 263-271. [CrossRef] [PubMed] 
3. USEPA. Literature Review of Contaminants in Livestock and Poultry Manure and Implications for Water Quality; EPA 820-R-13-002; USEPA, Office of Water: Washington, DC, USA, 2013; pp. 1-137.

4. Holm-Nielsen, J.B.; Seadi, T.A.; Oleskowicz-Popiel, P. The future of anaerobic digestion and biogas utilisation. Bioresour. Technol. 2009, 100, 5478-5484. [CrossRef] [PubMed]

5. Zhang, X.X.; Zhang, T.; Fang, H.H.P. Antibiotic resistance genes in water environment. Appl. Microbiol. Biotechnol. 2009, 82, 397-414. [CrossRef] [PubMed]

6. Sarmah, A.K.; Meyer, M.T.; Boxall, A.B. A global perspective on the use, sales, exposure pathways, occurrence, fate and effects of veterinary antibiotics (VAs) in the environment. Chemosphere 2006, 65, 725-759. [CrossRef] [PubMed]

7. Xu, P.; Zhou, X.; Xu, D.; Xiang, Y.; Ling, W.; Chen, M. Contamination and risk assessment of estrogens in livestock manure: A case study in Jiangsu province, China. Int. J. Environ. Res. Public Health 2018, 15, 125. [CrossRef]

8. Martinez-Carballo, E.; Gonzalez-Barreiro, C.; Scharf, S.; Gans, O. Environmental monitoring study of selected veterinary antibiotics in animal manure and soils in Austria. Environ. Pollut. 2007, 148, 570-579. [CrossRef] [PubMed]

9. Qian, M.; Wu, H.; Wang, J.; Zhang, H.; Zhang, Z.; Zhang, Y.; Lin, H.; Ma, J. Occurrence of trace elements and antibiotics in manure-based fertilizers from the Zhejiang Province of China. Sci. Total Environ. 2016, 559, 174-181. [CrossRef]

10. Arikan, O.A.; Sikora, L.J.; Mulbry, W.; Khan, S.U.; Rice, C.; Foster, G.D. The fate and effect of oxytetracycline during the anaerobic digestion of manure from therapeutically treated calves. Process Biochem. 2006, 41, 1637-1643. [CrossRef]

11. Ho, Y.B.; Zakaria, M.P.; Latif, P.A.; Saari, N. Degradation of veterinary antibiotics and hormone during broiler manure composting. Bioresour. Technol. 2013, 131, 476-484. [CrossRef]

12. Derby, N.E.; Hakk, H.; Casey, F.X.M.; DeSutter, T.M. Effects of composting swine manure on nutrients and estrogens. Soil Sci. 2011, 176, 91-98. [CrossRef]

13. Zhang, M.; He, L.Y.; Liu, Y.S.; Zhao, J.L.; Liu, W.R.; Zhang, J.N.; Chen, J.; He, L.K.; Zhang, Q.Q.; Ying, G.G. Fate of veterinary antibiotics during animal manure composting. Sci. Total Environ. 2019, 650, 1363-1370. [CrossRef] [PubMed]

14. Zhang, H.; Shi, J.; Liu, X.; Zhan, X.; Chen, Q. Occurrence and removal of free estrogens, conjugated estrogens, and bisphenol A in manure treatment facilities in East China. Water Res. 2014, 58, 248-257. [CrossRef] [PubMed]

15. Soares, O.S.G.P.; Rodrigues, C.S.; Madeira, L.M.; Pereira, M.F.R. Heterogeneous Fenton-Like Degradation of p-Nitrophenol over Tailored Carbon-Based Materials. Catalysts 2019, 9, 258. [CrossRef]

16. Gagol, M.; Przyjazny, A.; Boczkaj, G. Highly effective degradation of selected groups of organic compounds by cavitation based AOPs under basic pH conditions. Ultrason. Sonochem. 2018, 45, 257-266. [CrossRef] [PubMed]

17. Garoma, T.; Umamaheshwar, S.K.; Mumper, A. Removal of sulfadiazine, sulfamethizole, sulfamethoxazole, and sulfathiazole from aqueous solution by ozonation. Chemosphere 2010, 79, 814-820. [CrossRef] [PubMed]

18. Bhuta, H. Advanced treatment technology and strategy for water and wastewater management. In Industrial Wastewater Treatment, Recycling and Reuse, 1st ed.; Ranade, V.V., Bhandari, V.M., Eds.; Butterworth-Heinemann: Waltham, UK, 2014; Chapter 4; pp. 193-213.

19. Ramirez, J.H.; Maldonado-Hódar, F.J.; Pérez-Cadenas, A.F.; Moreno-Castilla, C.; Costa, C.A.; Madeira, L.M. Azo-dye Orange II degradation by heterogeneous Fenton-like reaction using carbon-Fe catalysts. Appl. Catal. B Environ. 2007, 75, 312-323. [CrossRef]

20. Mendez-Arriaga, F.; Esplugas, S.; Gimenez, J. Degradation of the emerging contaminant ibuprofen in water by photo-Fenton. Water Res. 2010, 44, 589-595. [CrossRef]

21. Sun, M.; Xu, D.; Ji, Y.; Liu, J.; Ling, W.; Li, S.; Chen, M. Using Fenton oxidation to simultaneously remove different estrogens from cow manure. Int. J. Environ. Res. Public Health. 2016, 13, 917. [CrossRef]

22. Uslu, M.O.; Balcioglu, I.A. Simultaneous removal of oxytetracycline and sulfamethazine antibacterials from animal waste by chemical oxidation processes. J. Agric. Food Chem. 2009, 57, 11284-11291. [CrossRef]

23. Wang, J.; Xia, K.; Waigi, M.G.; Gao, Y.; Odinga, E.S.; Ling, W.; Liu, J. Application of biochar to soils may result in plant contamination and human cancer risk due to exposure of polycyclic aromatic hydrocarbons. Environ. Int. 2018, 121, 169-177. [CrossRef] 
24. Ben, W.; Qiang, Z.; Pan, X.; Chen, M. Removal of veterinary antibiotics from sequencing batch reactor (SBR) pretreated swine wastewater by Fenton's reagent. Water Res. 2009, 43, 4392-4402. [CrossRef]

25. Bouasla, C.; Samar, M.E.H.; Ismail, F. Degradation of methyl violet 6B dye by the Fenton process. Desalination 2010, 254, 35-41. [CrossRef]

26. Cuiping, B.; Wenqi, G.; Dexin, F.; Mo, X.; Qi, Z.; Shaohua, C.; Zhongxue, G.; Yanshui, Z. Natural graphite tailings as heterogeneous Fenton catalyst for the decolorization of rhodamine B. Chem. Eng. J. 2012, 197, 306-313. [CrossRef]

27. Li, Y.; Zhang, A. Removal of steroid estrogens from waste activated sludge using Fenton oxidation: Influencing factors and degradation intermediates. Chemosphere 2014, 105, 24-30. [CrossRef]

28. Duarte, F.; Morais, V.; Maldonado-Hódar, F.J.; Madeira, L.M. Treatment of textile effluents by the heterogeneous Fenton process in a continuous packed-bed reactor using Fe/activated carbon as catalyst. Chem. Eng. J. 2013, 232, 34-41. [CrossRef]

29. Sun, J.H.; Sun, S.P.; Wang, G.L.; Qiao, L.P. Degradation of azo dye Amido black 10B in aqueous solution by Fenton oxidation process. Dyes Pigments 2007, 74, 647-652. [CrossRef]

30. Ghiselli, G.; Jardim, W.F.; Litter, M.I.; Mansilla, H.D. Destruction of EDTA using Fenton and photo-Fenton-like reactions under UV-A irradiation. J. Photochem. Photobiol. A Chem. 2004, 167, 59-67. [CrossRef]

31. Primo, O.; Rivero, M.J.; Ortiz, I. Photo-Fenton process as an efficient alternative to the treatment of landfill leachates. J. Hazard. Mater. 2008, 153, 834-842. [CrossRef]

32. Zhang, H.; Choi, H.J.; Huang, C.P. Optimization of Fenton process for the treatment of landfill leachate. J. Hazard. Mater. 2005, 125, 166-174. [CrossRef]

33. Heredia, J.B.D.; Domínguez, J.R.; López, R. Advanced oxidation of cork-processing wastewater using Fenton's reagent: Kinetics and stoichiometry. J. Chem. Technol. Biotechnol. 2004, 79, 407-412. [CrossRef]

34. Turan-Ertas, T.; Gurol, M.D. Oxidation of diethylene glycol with ozone and modified Fenton processes. Chemosphere 2002, 47, 293-301. [CrossRef]

35. Lopez, A.; Pagano, M.; Volpe, A.; Pinto, A.C.D. Fenton's pre-treatment of mature landfill leachate. Chemosphere 2004, 54, 1005-1010. [CrossRef]

36. Fei, H.Y.; Chang, Z.Z.; Wang, S.M.; Huang, H.Y.; Chen, X.; Zhu, H. Characterization of moisture in three livestock manures. J. Agro Environ. Sci. 2006, 25, 599-603. (In Chinese)

37. Nieto, L.M.; Hodaifa, G.; Rodríguez, S.; Giménez, J.A.; Ochando, J. Degradation of organic matter in olive-oil mill wastewater through homogeneous Fenton-like reaction. Chem. Eng. J. 2011, 173, 503-510. [CrossRef]

38. Sillanpaa, M.; Ncibi, M.C.; Matilainen, A. Advanced oxidation processes for the removal of natural organic matter from drinking water sources: A comprehensive review. J. Environ. Manag. 2018, 208, 56-76. [CrossRef]

39. Chi, G.; Chen, X.; Shi, Y.; Zheng, T. Forms and profile distribution of soil Fe in the Sanjiang Plain of Northeast China as affected by land uses. J. Soils Sediments 2010, 10, 787-795. [CrossRef]

40. Zhao, L.; Dong, Y.H.; Wang, H. Residues of veterinary antibiotics in manures from feedlot livestock in eight provinces of China. Sci. Total Environ. 2010, 408, 1069-1075. [CrossRef]

41. Agriculture Department of People Republic China. Organic Fertilizer; NY 525-2012; China Agriculture Press: Beijing, China, 2012. (In Chinese)

(C) 2019 by the authors. Licensee MDPI, Basel, Switzerland. This article is an open access article distributed under the terms and conditions of the Creative Commons Attribution (CC BY) license (http://creativecommons.org/licenses/by/4.0/). 